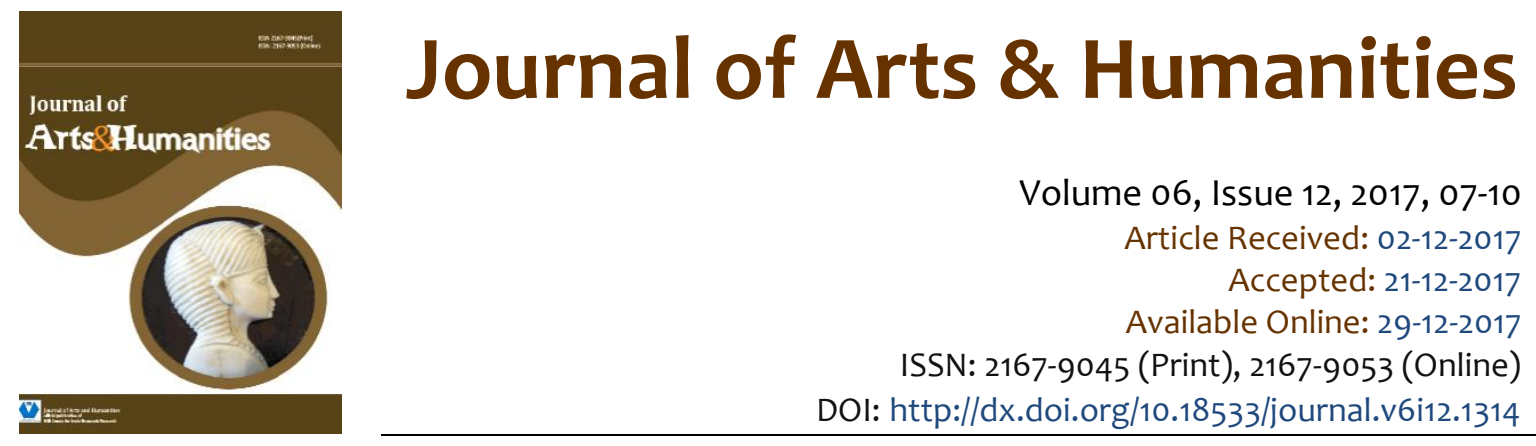

\title{
The Role of Translation in EFL Writing ${ }^{1}$
}

\author{
Zhao Congmin ${ }^{2}$
}

\begin{abstract}
This paper explores the problem "thinking in the first language then translating into the target language" by examining the process of writing. It is suggested that it is natural to think in the first language and/or to translate and the first language to foreign language translation indirectly enhances the writing ability.
\end{abstract}

Keywords: Target Language, Translation, Writing Process.

This is an open access article under Creative Commons Attribution 4.0 License.

\section{Introduction}

The goals of second or foreign language learning are defined as the fostering of four skills of listening, reading, speaking and writing. As a fundamental and complicated language skill, writing proves to be a challenging task for language learners. Writing itself involves the use of appropriate language to express ideas and organize them into discoursal texts as is required by the writing conventions of given genre tasks. It presents to be a tough process for students, it is even more so for English as a foreign language (EFL) or English as a second language (ESL) learners.

For second language (L2) or foreign language learners, one persistent problem for $L 2$ writing is "thinking in the first language then translating into the target language". This is especially true of low and intermediate learners. This seems to go against the fundamental principle of second language acquisition (SLA): think in the target language and do not translate. Chinese learners of English confront the same situation that is they think in Chinese then translate into English. Consequently the language produced is likely to be Chinglish either in terms of vocabulary or structure. Levenston (1971: 115) notes one feature of non-native use of a second language is "the excessive use ("over-indulgence") of clause( or group) structures which closely resemble translation equivalents in mother tongue, or L1, to the exclusion of other structures ("under-representation") which are less like anything in L1". Similarly, Perkins comments that many L2 structures produced by L2 learners "often sounds formal or stilted to ears of L2 native speaker, although the utterance is both grammatically and lexically acceptable".

\footnotetext{
1 This paper is sponsored by the Fundamental Research Fund 2014MS78 in North China Electric Power University for Central Higher Education Universities.

2 North China Electric Power University. Beijing, China.
} 
To what extent does translation affect learners' overall writing performance? Should translation be blamed for the low quality of writing? This paper dwells on the importance of language aspect in writing by citing and comparing the writing criteria of international tests and then attempt to explore the issue of translation by analysing the writing process.

\section{The importance of language in writing}

Some learners may have a tacit assumption that writing is all about language proficiency. There are even a minority of teachers who tend to rate students' work of writing mainly on the basis of the number of language errors. The fact is language is just an essential component of writing while content and organization are higher order aspects of writing. Language proficiency will certainly impede the clear deliverance of ideas. The use of English such as vocabulary and sentence variety is a fundamental step towards writing proficiency.

How does the language aspect figure or weigh in writing? Insights might be provided by referring to the writing criteria of the influential international standardized tests, like TOFEL, GRE and IELTS. For IELTS writing, lexical resource and grammatical range and accuracy are involved: "uses a wide range of vocabulary with very natural and sophisticated control of lexical features; rare minor errors occur only as 'slips'; uses a wide range of structures with full flexibility and accuracy; rare minor errors occur only as 'slips'". TOFEL iBT test dictates writing "displays consistent facility in the use of language, demonstrating syntactic variety, appropriate word choice and idiomaticity, though it may have minor lexical or grammatical errors". GRE writing test "assesses critical thinking and analytical writing skills", the highest band description of language use ability is "skillfully uses sentence variety and precise vocabulary to convey meaning effectively".

The rating criteria of the tests are similar in the language aspect: the natural or appropriate use of vocabulary and variety in syntactic structure. This roughly corresponds to Bachman's grammatical knowledge and sociolinguistic knowledge. According to Bachman and Palmer (2010), language use ability consists of language knowledge and strategic competence. Language knowledge is subdivided into organizational knowledge (grammatical knowledge and textual knowledge) and pragmatic knowledge (functional knowledge and sociolinguistic knowledge).

With some knowledge of the language requirements for writing, it will be easier to understand the writing process.

\section{The writing process}

At present a process approach to writing gains widespread acceptance. Writing is not only a product, but more importantly and essentially a process.

\subsection{The writing process}

Writing is a recursive process. Generating ideas, organizing, writing, and revision form cycles. Flower and Hayes model of the writing process consist of three modules: task environment, the writer's long term memory, and monitor. Inside the monitor module there are the processes of planning, translating and reviewing. Flower and Hayes call the process of drafting translating. They especially single out a translating process is to "take material from memory under the guidance of the writing plan and to transform it into acceptable written English sentences". (1980:15)

Flower and Hayes' postulation of the writing process provide a basic understanding of the picture, though there are updated versions and other models, such as Bereiter and Scardamalia (1987). What follows is a discussion of the thinking process and product which hopefully can further the knowledge of the writing process.

\subsection{Think in L1 or L2?}

When people are thinking, what forms does ideas take? People either think in non-verbal (such as images, symbols or pictures) or verbal languages. Thought and language can't be separated. Only verbalized thoughts can be understood. Yet it is still hard to capture the mechanism of conceptualizing. Psycholinguists and cognitive linguists assume that ideas exist as a kind of "mentalese" before they are put into words. As regards to the properties of this pre-linguistic mental representation, there is no conclusive consensus. 
How do language and thought interact in completing cognitive tasks? The answer to this question is more complicated in the case of bilinguals and multilinguals. Cohen's (2000) review of research indicates that learners do not think complex thoughts in target language (TL), making passing reference to it as fleeting /limited thoughts; most or all metalinguistic tasks are performed in L1 and multilingual learners may draw material from several languages while learning TL. Thinking in L1 reduces load on working memory and saves cognitive processing resource. Therefore, they conclude that "it pays to do systematic thinking through TL, but don't hesitate about thinking in L1 when it is comforting and necessary".

The extent of TL thinking varies from minimal, passing thoughts (one or two words) to more extensive and deeper thoughts. Proficiency limits thoughts in TL, but it does not mean that low proficiency learners cannot think in the TL at all. Cohen and Brooks-Carson think that inner speech may be incomplete in grammar and vocabulary and difficult to interpret when self-directed (2001).

\subsection{L2 language production}

According to Levelt, Roelofs and Meyer (1998), word production entails four stages of conceptual preparation, lemma selection, morphonological encoding, and computation of a phonetic articulary gesture.

As for speech production, there are the serial models of linguistic planning as advocated by Fromkin and Garrett and the parallel models of linguistic planning. The former tends to view speech planning as a series of stages, each devoted to one level of linguistic planning. The latter maintains the simultaneous processing of multiple levels: semantic, syntactic, morphological, and phonological. A plausible view might be the interaction of both the serial and parallel processes.

An overview of the mechanism in thinking and language production facilitate our understanding of the process of writing.

\section{4. $\quad$ Role of translation in L2 writing}

The activity of planning content of utterances in L1 and then formulating them as effectively as possible in $L 2$ is a very natural one. Translation is an inevitable step EFL writing. Psycholinguistic literature suggests the connection between concepts and $L 1$ is much stronger than between concepts and L2. Translation reduces the load on working memory. (Cohen and Brooks-Carson 2001). It is difficult to handle complex ideas in L2. Without the processing load of L2 vocabulary and syntax, learners can do their best in generating ideas and organizing them in logical order in the planning phase of the writing process. In L2 production, there is always the time when meaning cannot be put across in L2 or the appropriate L2 words for some concepts fail to be retrieved. Then translation comes to help fill in the gap by activating translation equivalents of ideas or concepts. Even learners of higher proficiency levels tend to turn to L1 in the writing process. With increasing access to $L 2$ written text in given topics and genres, learners will gain more control: the language production process will become more automatic and think more in L2.

Cohen and Brooks-Carson compare direct writing in L2 and translated writing. Their study shows that thinking through L1 may be a benefit for some students in certain writing tasks and proves the value of generating tr strategy training materials (2001).

L1-L2 translation and L2 writing are similar in that they are both productive skills. Translation from L1 to L2 can somehow be equated with composition writing tasks (Leonardo 2010:95). L1-L2 translation is more a test of $\mathrm{L} 2$ productive use skills.

Translation is a specific form of language use. While performing translation tasks, learners just need to focus on rendering ideas into English, without the need to worry about the generation of ideas and logical organization of ideas. So cognitive resource can be devoted to getting meaning across by manoeuvring FL knowledge. Perkins (53) believes that "the structural and semantic resources of language are so great that translating from $L 1$ to $L 2$ is inevitably faced with a plurality of $L 2$ equivalents to choose from, and it is this complex diversity of choice that cannot easily be pinned down and categorized". The rehearsal of language in L2 will be bound to lead to language proficiency growth. Ellis and Sinclair (1996) show that as "L2 learners hear and produce L2 words, they implicitly acquire knowledge of the statistical frequencies and sequential probabilities of the phonotactics of L2. This is 
one reason why translation is integrated into some foreign language tests". For instance, the Band 4 and Band 6 English test in China available to Chinese college students included Chinese-English translation which aims to introduce Chinese culture to the outside world. What such translation activities may seem insufficient or ineffective in view of EFL writing is that the fields covered or topics may not overlap much.

With training of translation strategies, learners will gradually get away from literal or word-for-word translation and render ideas into grammatically correct and stylistically appropriate L2. Chinese-English translation focuses.

With learners' proficiency with L2 enhancing and increasing accumulation of English writing texts, learners are able to do more thinking in English and less likely to resort to translation.

Overall, translation is a necessary and natural process in the process of transforming ideas into English in L2 writing.

\section{Conclusion}

Translation is inevitable in EFL writing. Learners can't engage in completely thinking in English even if they strive to do so due to constraints of FL proficiency. This is also true of highly proficient learners. Thinking in English either as L2 or FL may be best treated as a goal. Translation trains the transferring of meaning between languages and $\mathrm{L}_{1}$ to $\mathrm{L} 2$ or foreign language in particular approximates FL writing. Topics may sometimes not correspond in terms of fields. Rehearsal of FL vocabulary and structural knowledge and discourse knowledge is bound to move learners one step forward toward language acquisition and communicative use of that language.

\section{References}

Bachman, L. F. and Palmer, A. S. (2010). Language Assessment in the Real World. Oxford: OUP. Cohen, A. D. (2000). Strategies in learning and using a second language. Beijing: Fltrp.

Cohen, A. D. and Brooks-Carson, Amanda. (2001). Research on Direct versus Translated Writing: Students' Strategies and Their Results. The Modern Language Journal: 85, 169-188.

Ellis, N. C., \& Sinclair, S. (1996). Working Memory in the Acquisition of Vocabulary and Syntax: Putting Language in Good Order. Quarterly Journal of Experimental Psychology Section A, 49, 234-250.

Flower, L. and Hayes, J. (1980). The dynamics of composing: Making plans and juggling constraints. In L. W. Gregg and E. R. Steinberg (eds.), Cognitive processes in writing. Hillsdale, NJ: Lawrence Erlbaum Associates.

Leonardi, Vanessa. (2010). The Role of Pedagogical Translation in Second Language Acquisition: From Theory To Practice. Bern, New York: Peter Lang.

Levenston, E. A. (1971). Over-indulgence and under-representation - aspects of mother-tongue interference. In Nickel, G. (ed.). Papers in Contrastive Linguistics. New York: Cambridge University Press, 115-121.

Perkins, Chris. (1985). Sensitizing advanced learners to problems of L1-L2 translation. In Christopher Titford / A.E. Hieke (eds.) Translation in Foreign Language Teaching and Testing. Tubingen: Gunter Narr, 51-72.

Weigle, Sara Cushing. (2011). Assessing Writing. Beijing: Fltrp.

\section{Web link}

https://www.ielts.org/ielts-for-organisations/ielts-scoring-in-detail. 